\title{
Differential effects of dietary fatty acids on the cerebral distribution of plasma-derived apo B lipoproteins with amyloid- $\beta$
}

\author{
Ryusuke Takechi ${ }^{1,2,3}$, Susan Galloway ${ }^{1,2,3}$, Menuka M. S. Pallebage-Gamarallage ${ }^{1,2,3}$, \\ Cheryl L. Wellington ${ }^{4}$, Russell D. Johnsen ${ }^{5,6}$, Satvinder S. Dhaliwal ${ }^{1,2,3}$ and John C. L. Mamo ${ }^{1,2,3 *}$ \\ ${ }^{1}$ Faculty of Health Science, School of Public Health, Curtin University of Technology, Bentley, WA, Australia \\ ${ }^{2}$ The Curtin Health Innovation Research Institute, Bentley, WA, Australia \\ ${ }^{3}$ The Australian Technology Network, Centre for Metabolic Fitness, Perth, WA, Australia \\ ${ }^{4}$ Department of Pathology and Laboratory Medicine, University of British Columbia, Vancouver, BC, Canada \\ ${ }^{5}$ Centre for Neuromuscular and Neurological Disorders, University of Western Australia, Nedlands, WA, Australia \\ ${ }^{6}$ The Australian Neuromuscular Research Institute, Nedlands, WA, Australia
}

(Received 5 June 2009 - Revised 26 August 2009 - Accepted 27 August 2009 - First published online 28 October 2009)

Some dietary fats are a risk factor for Alzheimer's disease (AD) but the mechanisms for this association are presently unknown. In the present study we showed in wild-type mice that chronic ingestion of SFA results in blood-brain barrier (BBB) dysfunction and significant delivery into the brain of plasma proteins, including apo B lipoproteins that are endogenously enriched in amyloid- $\beta$ (A $\beta$ ). Conversely, the plasma concentration of S100B was used as a marker of brain-to-blood leakage and was found to be increased two-fold because of SFA feeding. Consistent with a deterioration in BBB integrity in SFA-fed mice was a diminished cerebrovascular expression of occludin, an endothelial tight junction protein. In contrast to SFA-fed mice, chronic ingestion of MUFA or PUFA had no detrimental effect on BBB integrity. Utilising highly sensitive three-dimensional immunomicroscopy, we also showed that the cerebral distribution and co-localisation of A $\beta$ with apo B lipoproteins in SFA-fed mice are similar to those found in amyloid precursor protein/presenilin-1 (APP/PS1) amyloid transgenic mice, an established murine model of AD. Moreover, there was a strong positive association of plasma-derived apo B lipoproteins with cerebral A $\beta$ deposits. Collectively, the findings of the present study provide a plausible explanation of how dietary fats may influence AD risk. Ingestion of SFA could enhance peripheral delivery to the brain of circulating lipoprotein $-\mathrm{A} \beta$ and exacerbate the amyloidogenic cascade.

Alzheimer's disease: Amyloid-ß: Blood-brain barrier: SFA: TAG-rich lipoproteins

An accumulating body of evidence is consistent with the concept that the onset and progression of Alzheimer's disease (AD) is influenced by lifestyle factors including nutrition ${ }^{(1)}$. Several population studies have found that SFA are a positive risk factor for $\mathrm{AD}^{(2-3)}$ and in animal models of $\mathrm{AD}$, SFA or cholesterol feeding markedly exacerbates cerebral pathology ${ }^{(4-5)}$. However, the mechanisms that link dietary fat to the pathogenesis of $\mathrm{AD}$ are unclear.

The cerebrovasculature in subjects with AD shows pathological alterations including vascular endothelial and smooth muscle cell proliferation ${ }^{(6)}$. Blood plasma proteins have been detected in the parenchyma of $\mathrm{AD}$ brains ${ }^{(7-8)}$ and inflammatory sequalae are commonly reported ${ }^{(9-10)}$, observations that are consistent with breakdown of the blood-brain barrier (BBB). Yet despite evidence supportive of $\mathrm{AD}$ having an underlying vascular component, most research focuses on damage of neurons ${ }^{(11)}$.

A major neuropathological marker of $\mathrm{AD}$ is amyloid- $\beta$ (A $\beta)$ deposition in the cerebrovasculature and in the cerebral parenchyma. Derived from amyloid precursor protein (APP), $\mathrm{A} \beta$ is the predominant component of amyloid plaque $^{(12)}$. The source of cerebral $A \beta$ deposits in $A D$ is uncertain, though there is little evidence for increased cerebral $\mathrm{A} \beta$ production in sporadic, late-onset $\mathrm{AD}$ which accounts for over $96 \%$ of $\mathrm{AD}$ cases. Rather, decreased $\mathrm{A} \beta$ clearance across the $\mathrm{BBB}$ via receptor pathways and/or via the choroid plexus has been suggested as an initiating pathway for amyloidosis $^{(13-15)}$. More recent has been evidence of bloodto-brain delivery of circulating $A \beta$, a process that would conceivably exacerbate parenchymal load in the absence of compensatory clearance pathways ${ }^{(16)}$.

Plasma A $\beta$ can be derived from vascular smooth muscle cells and endothelial cells, or from blood platelets. However, another significant source of plasma $A \beta$ may be from lipogenic organs such as the small intestine and liver ${ }^{(17-19)}$. Hepatocytes and absorptive epithelial cells of the small intestine (enterocytes) secrete $A \beta$ as a lipoprotein complex, and in the small intestine this pathway is under dietary regulation ${ }^{(17-20)}$.

Abbreviations: A $\beta$, amyloid- $\beta$; AD, Alzheimer's disease; APP, amyloid precursor protein; BBB, blood-brain barrier; BS, brain stem; CTX, cortex, excluding the hippocampus; 3-D, three-dimensional; HPF, hippocampal formation; PS1, presenilin-1; TRL, TAG-rich lipoprotein; vWF, von-Willebrand factor.

* Corresponding author: Professor John Mamo, fax +61 892662958 , email J.Mamo@Curtin.edu.au 
Chronic ingestion of SFA was reported to significantly enhance enterocytic abundance of $A \beta$ and conversely the protein could not be detected when animals were fasted ${ }^{(17)}$.

Distributional analysis of plasma lipoprotein-A $\beta$ in normal subjects and those with $\mathrm{AD}$ or mild cognitive impairment (MCI) is consistent with the notion that dietary-induced $\mathrm{A} \beta$ may contribute to the aetiology of $\mathrm{AD}^{(21)}$. In control and in $\mathrm{AD} / \mathrm{MCI}$ subjects, greater than $60 \%$ of plasma lipoprotein-A $\beta$ was found to be associated with TAG-rich lipoproteins (TRL); however, this was significantly increased in $\mathrm{AD} /$ MCI subjects $v$. controls. Moreover, whilst the AD subjects were normolipidaemic and had similar plasma levels of hepatically derived lipoproteins, the concentration of apo B48 (an exclusive marker of chylomicrons) was elevated more than three-fold in post-absorptive AD subjects. Increased apo B48 is indicative of postprandial dyslipidaemia, an exaggerated rise in plasma chylomicrons that occurs following the ingestion of dietary fats ${ }^{(22)}$. Consistent with the notion of an $A \beta$ postprandial response, ingestion of a lipid-enriched meal was found to cause a transient increase in the plasma concentration of APP and of $A \beta$ in otherwise healthy subjects ${ }^{(23)}$.

Evidence of a causal link between plasma lipoprotein-A $\beta$ and $\mathrm{AD}$ also comes from studies in animal models of $\mathrm{AD}$. In transgenic mice that over-express APP, plasma A $\beta$ concentration correlated with secretion rates into the blood of TRL, which was increased 3- to 8-fold above wild-type controls ${ }^{(24)}$. Furthermore, there was a positive association between plasma TRL-A $\beta$ secretion with onset of cerebrovascular and parenchymal amyloidosis ${ }^{(25)}$.

The mechanisms by which circulating $\mathrm{A} \beta$ increases AD risk are presently unclear. However, several studies have provided evidence of a vasoactive role of $A \beta$, with pathological manifestations before $A \beta$ deposition ${ }^{(26-28)}$. $A \beta$ is vasoconstrictive and vessels treated with $A \beta$ show significant endothelial cell damage, with changes in the cell membrane, cytoplasm, nucleus and other organelles.

We hypothesise that SFA may adversely influence BBB function, because of exaggerated exposure to plasma lipoprotein $-A \beta$ that leads to greater rates of plasma to cerebral $A \beta$ delivery. In previous studies, integrity of the BBB has been assessed in experimental colitis ${ }^{(29)}$ and following acute intravenous injection of solubilised, exogenous $A \beta^{(26-28)}$. Consistent with the notion that lipoproteins have an important role in central nervous system diseases, Kay et al. reported significant remodelling of cerebrospinal fluid lipoproteins after subarachnoid haemorrhage ${ }^{(30)}$. However, the potential effect of SFA on plasma $\mathrm{A} \beta$ homeostasis and $\mathrm{BBB}$ function have not been reported. If this hypothesis is correct, it may explain epidemiological data that link SFA intake with $\mathrm{AD}$ risk. In the present study we directly explore BBB integrity in wild-type mice fed fatty acid-enriched diets.

\section{Materials and methods}

\section{Animals}

Female C57BL/6J mice, aged 6 weeks, were purchased from the Animal Resource Centre (Perth, WA, Australia). Mice were randomly allocated to either the control or one of three fatty acid treatment groups (see Dietary intervention in wild-type mice section). Mice were maintained in an accredited animal holding facility with regulated temperature, air pressure and lighting ( $12 \mathrm{~h}$ light $-12 \mathrm{~h}$ dark). Mice had ad libitum access to feed and water. At 3 and 6 months following commencement of the dietary intervention, six mice from each group were killed by cardiac exsanguination under complete anaesthesia. The C57BL6J mice were considered an appropriate wild-type strain because the transgenic APP/presenilin-1 (APP/PS1) mice are a C57BL6J $\times$ C3H strain.

Double transgenic APP/PS1 mice develop AD-like brain pathology after 20 weeks of age. In the present study APP/ PS1 mice were fed a standard low-fat rodent chow and killed at 12 months of age.

All experimental procedures used in this project were approved by a National Health and Medical Research Council (Australia) accredited Animal Ethics Committee (Curtin University approval no. R34/08).

\section{Dietary intervention in wild-type mice}

The feed preparations were made by Glenn Forest Stock Feeders (Perth, WA, Australia). The low-fat control diet was a standard American Institute of Nutrition AIN-93M rodent chow containing $<4 \% \quad(\mathrm{w} / \mathrm{w})$ fat as polyunsaturates, with $<1 \%$ total digestible energy as lipids and was free of cholesterol (for details, see Table 1). All of the fat-enriched diets comprised $40 \%$ total digestible energy as lipids (or $20 \cdot 3 \%, w / w)$. For the SFA intervention group, the principal fatty acid types were palmitic $(16: 0)$ and stearic $(18: 0)$ $(13 \%, \mathrm{w} / \mathrm{w})$ but the SFA diet also contained some oleic acid (18:1n-9, 6\%, w/w). The MUFA diet contained approximately $16 \%$ as oleic acids, approximately $1.5 \%$ as SFA and only trace amounts of PUFA. The PUFA-enriched diet was principally made up of DHA (22:6n-3), EPA (20:5n-3) and oleic acid. SFA and MUFA accounted for less than $4 \%$ (w/w) of the PUFA-enriched diet. The MUFA and PUFA diets reflected blends of Sunola ${ }^{\mathrm{TM}}$ oil and fish oils, respectively.

\section{Tissue and plasma sample collection}

Following dietary intervention for 3 or 6 months, mice were anaesthetised with pentobarbitone and blood samples obtained by cardiac puncture. Plasma was separated by low-speed centrifugation and stored immediately at $-80^{\circ} \mathrm{C}$. Brains were carefully removed and washed in chilled PBS. For immunofluorescent microscopy, the right hemisphere was segmented and fixed in $4 \%$ paraformaldehyde for $24 \mathrm{~h}$ followed by cryoprotection in $20 \%$ sucrose solution for $3 \mathrm{~d}$ at $4^{\circ} \mathrm{C}$. Tissues were then frozen in isopentane/dry ice and stored at $-80^{\circ} \mathrm{C}$.

\section{Plasma S100B and amyloid- $\beta$ analysis}

Plasma S100B was measured by ELISA (CosmoBio, Tokyo, Japan) according to the instructions provided by the manufacturer. Briefly, $20 \mu 1$ of plasma samples, or of the S100B standards $(0,98,197,394,1575,3150$ and $6300 \mathrm{pg} / \mathrm{ml}$ ) were incubated overnight at $4^{\circ} \mathrm{C}$ in ninety-sixwell microplates coated with the primary antibody. Thereafter, plates were incubated with the conjugated secondary 
Table 1. Dietary composition data sheet*

(Percentages)

\begin{tabular}{|c|c|c|c|c|}
\hline Diet... & Control & SFA & MUFA & PUFA \\
\hline Total fat & 4 & $20 \cdot 3$ & $20 \cdot 3$ & $20 \cdot 3$ \\
\hline Total digestible energy from lipids & $\mathrm{n} / \mathrm{a}$ & 40 & 40 & 40 \\
\hline SFA, $12: 0$ and less & $\mathrm{n} / \mathrm{a}$ & $\mathrm{n} / \mathrm{a}$ & Not detected & $\mathrm{n} / \mathrm{a}$ \\
\hline Myristic acid (14:0) & Trace & 0.05 & 0.02 & 0.54 \\
\hline Pentadecanoic acid (15:0) & $\mathrm{n} / \mathrm{a}$ & 0.01 & $\mathrm{n} / \mathrm{a}$ & $0 \cdot 16$ \\
\hline Palmitic acid $(16: 0)$ & 0.20 & $5 \cdot 16$ & 0.85 & $3 \cdot 26$ \\
\hline Magaric acid $(17: 0)$ & $\mathrm{n} / \mathrm{a}$ & 0.05 & $\mathrm{n} / \mathrm{a}$ & 0.18 \\
\hline Stearic acid $(18: 0)$ & $0 \cdot 10$ & $7 \cdot 31$ & 0.87 & 0.92 \\
\hline Arachidic acid $(20: 0)$ & $\mathrm{n} / \mathrm{a}$ & 0.24 & $\mathrm{n} / \mathrm{a}$ & 0.06 \\
\hline Behenic acid $(22: 0)$ & $\mathrm{n} / \mathrm{a}$ & 0.04 & $n / a$ & $\mathrm{n} / \mathrm{a}$ \\
\hline Tetracosanoic acid $(24: 0)$ & $\mathrm{n} / \mathrm{a}$ & 0.03 & $n / a$ & $\mathrm{n} / \mathrm{a}$ \\
\hline Palmitoleic acid $(16: 1)$ & Trace & 0.05 & 0.02 & 0.66 \\
\hline Heptadecenoic acid $(17: 1)$ & $\mathrm{n} / \mathrm{a}$ & 0.01 & $\mathrm{n} / \mathrm{a}$ & $0 \cdot 10$ \\
\hline Oleic acid $(18: 1 n-9)$ & 2.40 & $6 \cdot 62$ & $15 \cdot 70$ & $2 \cdot 25$ \\
\hline Gadoleic acid (20:1) & Trace & 0.01 & 0.07 & 0.18 \\
\hline Linoleic acid $(18: 2 n-6)$ & 0.80 & 0.67 & $2 \cdot 42$ & 0.23 \\
\hline$\alpha$-Linolenic acid $(18: 3 n-3)$ & $\mathrm{n} / \mathrm{a}$ & 0.05 & 0.13 & 0.09 \\
\hline$\gamma$-Linolenic acid $(18: 3 n-6)$ & 0.40 & Not detected & $\mathrm{n} / \mathrm{a}$ & 0.08 \\
\hline Stearidonic acid $(18: 4 n-3)$ & $\mathrm{n} / \mathrm{a}$ & $\mathrm{n} / \mathrm{a}$ & 0.08 & $\mathrm{n} / \mathrm{a}$ \\
\hline Arachidonic acid $(20: 4 n-6)$ & Trace & Not detected & 0.20 & 0.46 \\
\hline EPA $(20: 5 n-3)$ & Trace & Not detected & Not detected & 2.00 \\
\hline DPA (22:5n-3) & $\mathrm{n} / \mathrm{a}$ & Not detected & Not detected & 0.30 \\
\hline DHA $(22: 6 n-3)$ & Trace & Not detected & Not detected & $8 \cdot 22$ \\
\hline
\end{tabular}

$\mathrm{n} / \mathrm{a}$, Not applicable.

${ }^{*}$ Detailed dietary compositions of the diet of low-fat control, saturated fat (SFA), monounsaturated fat (MUFA) and polyunsaturated fat (PUFA) groups are given.

antibody for $2 \mathrm{~h}$, followed by $2 \mathrm{~h}$ incubation with streptavidin-horseradish peroxidase. Finally samples were incubated with substrate solution for $20 \mathrm{~min}$ and the reaction was terminated with stopping solution. The optical absorbance was measured at $490 \mathrm{~nm}$.

Plasma concentrations of mouse $A \beta_{1-40}$ and $A \beta_{1-42}$ were measured utilising Biosource ELISA kits (KMB3441; Invitrogen, Carlsbad, CA, USA) according to the manufacturer's instructions. Plasma $(100 \mu \mathrm{l})$ or $A \beta$ standards $\left(A \beta_{1-40}: 0\right.$, $7 \cdot 8,15 \cdot 6,31 \cdot 3,62 \cdot 5,125,250,500 \mathrm{pg} / \mathrm{ml} ; \mathrm{A} \beta_{1-42}: 0,3 \cdot 12$, $6 \cdot 25,12 \cdot 5,25,50,100,200 \mathrm{pg} / \mathrm{ml})$ were dispensed into wells and incubated for $2 \mathrm{~h}$ at room temperature, then thoroughly washed. The primary antibody for either $A \beta_{1-40}$ or $A \beta_{1-42}$ was then added and incubated for $1 \mathrm{~h}$ at room temperature. Anti-rabbit IgG-horseradish peroxidase was added for $30 \mathrm{~min}$, then incubated with stabilised chromogen for an additional $30 \mathrm{~min}$ in darkness. The optical absorbance was measured at $450 \mathrm{~nm}$.

Immunofluorescent detection of $\operatorname{IgG}$, apo B, occludin and von Willebrand factor in cerebral tissue

Cryosection specimens of $18 \mu \mathrm{m}$ were prepared from the right hemisphere of the brain of each mouse. For IgG detection, sections were incubated with polyclonal goat anti-mouse IgG antibody conjugated with Alexa 488 fluorochrome (1:100; Abcam, Inc., Cambridge, MA, USA) for $2 \mathrm{~h}$ at room temperature. Subsequently, the sections were imaged utilising an inverted fluorescent microscope (Zeiss AxioVert 200M; Carl Zeiss, Jena, Germany) and AxioVision software (version 4.6; Carl Zeiss).

Apo B lipoproteins were detected by overnight incubation with polyclonal rabbit anti-apo B antibody (1:200; Abcam, Inc.).
The primary antibody was then visualised with goat-anti-rabbit IgG conjugated with Alexa 488 (Invitrogen).

Negative controls were included for all immunofluorescent experiments and included replacement of the primary antibody with buffer, or an irrelevant serum. Fluorescent staining was not observed for any negative control tissue preparations.

\section{Fluorescent image capture and semi-quantitative measurement}

All fluorescent images were captured with a fluorescent microscope (AxioVert 200M) coupled to an MRm digital camera and managed by AxioVision software (version 4.6; Carl Zeiss). Three-dimensional (3-D) images were taken with ApoTome optical sectioning methodology (Carl Zeiss). Quantification was determined within the cortex excluding the hippocampus (CTX), hippocampal formation (HPF) and brain stem (BS).

For each mouse killed, a minimum of three cryosection specimens was prepared from the right hemisphere of the brain. For each specimen, up to seven 3-D ApoTome images were randomly taken within each designated region of the brain. For IgG and apo B quantitative measurement, images were captured at $\times 200$ magnification $(430 \times 322 \mu \mathrm{m})$. Each $3-\mathrm{D}$ image consisted of six to thirteen Z-stack images and the distance between Z-stack slices was $1.225 \mu \mathrm{m}$ optimised by Nyquist theory $(2 \times$ oversampling in axial direction). The optical densitometric sum for the protein of interest was determined in three dimensions $(1388 \times 1040$ pixel two-dimensional planes) utilising the automated optical density measurement tool (AxioVision; Carl Zeiss). 
Double immunofluorescent detection with two polyclonal antibodies

In order to detect two different proteins with two polyclonal antibodies raised in the same species, a double immunofluorolabelling method was used as we have previously described $^{(31)}$. For the co-localisation of $A \beta$ with perivascular leakage of plasma apo $\mathrm{B}$, rabbit polyclonal anti-A $\beta_{1-40 / 42}$ (Chemicon; Millipore, Billerica, MA, USA) and rabbit polyclonal anti-apo B antibodies were used. For the BBB tight junction protein occludin and the vascular endothelial cell marker von Willebrand factor (vWF), these were detected with rabbit polyclonal anti-occludin-1 (Invitrogen) and rabbit polyclonal anti-vWF antibodies (Abcam, Inc.). Briefly, $10 \mu \mathrm{m}$ sections were fixed in acetone for $3 \mathrm{~min}$ at $-20^{\circ} \mathrm{C}$ and heat-mediated antigen retrieval was achieved by incubating in a water-bath at $60^{\circ} \mathrm{C}$ for $3 \mathrm{~h}$. Endogenous biotin was blocked with avidin in egg white and biotin in skimmed milk. In order to avoid the cross-reaction of the two polyclonal antibodies, the concentration of the first antibody was diluted so that it was undetectable with conventional secondary antibody detection, but detectable after the signal amplification with the biotin-avidin reaction. Subsequently the second protein of interest was detected with standard secondary detection.

For the co-localisation analysis of $A \beta$ and apo $B$ in cerebral tissue of wild-type mice given different fatty acid-enriched diets, fifteen 3 -D images were captured at $\times 400$ magnification $(222 \times 166 \mu \mathrm{m})$. Each of the 3-D images contained thirty-two to seventy-one Z-stack images and the distance between $Z$-stack slices was $0.275 \mu \mathrm{m}$. From a total of 695 two-dimensional images, co-localisation of $A \beta$ and apo $B$ was then determined with AxioVision software and data were expressed as Manders' and Pearson's correlation coefficients. Manders' correlation coefficient estimates the co-localisation independent of fluorescent intensity, whereas Pearson's correlation coefficient explores if there is also an association in fluorescent intensities.
(A)

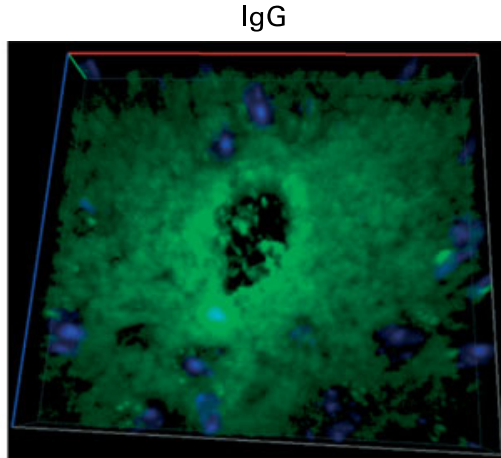

(B)
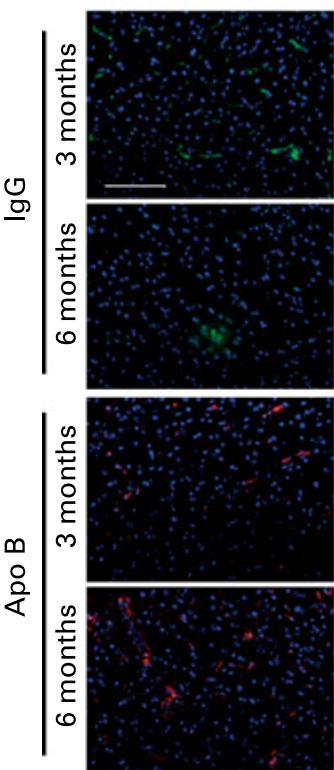

SFA
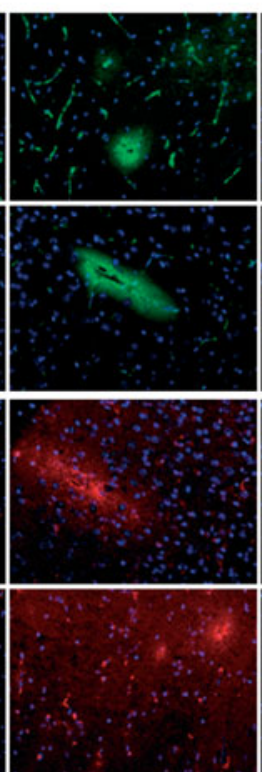

MUFA
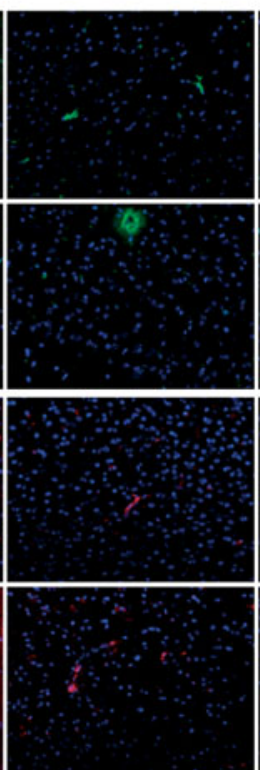

Apo B

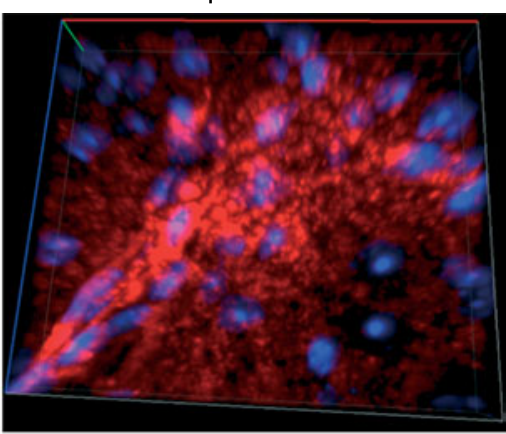

PUFA
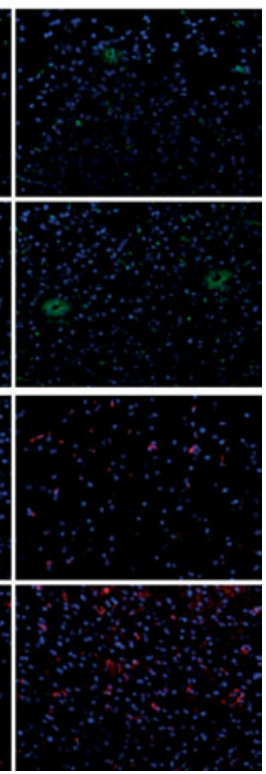

Fig. 1. Three-dimensional (3-D) immunodetection of cerebral IgG and apo B extravasation. Perivascular leakage of plasma IgG and apo $B$ into the brain was captured in 3-D utilising highly sensitive immunofluorescent microscopy techniques. IgG is shown in green and apo B is in red. 6-Diamidino-2-phenylindole (DAPI)counterstained nuclei are shown in blue. (A) Representative 3-D images of plasma IgG and apo B leakage observed in mice fed a SFA-rich diet for 6 months. Scales of $x$ (red), $y$ (red) and $z$ (green) axes are $90 \times 80 \times 10 \mu \mathrm{m}$. (B) Low magnification images of cerebral IgG and apo B immunoreactivity. Significant cerebral extravasation of IgG and apo B was seen in both 3 and 6 month SFA groups. The scale bar indicates $100 \mu \mathrm{m}$. 
For vWF and occludin measurement, 3-D ApoTome images were taken at $\times 200$ magnification. Each 3 -D image consisted of a minimum of three and up to seven Z-stack images and distance between Z-stack slices was $1.225 \mu \mathrm{m}$. To measure the relative abundance of $\mathrm{vWF}$, the optical densitometric sum within the image was determined and expressed as per vWF per volume of tissue. In order to measure occludin abundance specific for the cerebrovasculature, only occludin staining which co-localised with vWF was measured.

\section{Co-localisation of apo B with cerebral amyloid plaques}

To examine the co-localisation of apo B with amyloid plaques in 12-month-old APP/PS1 transgenic mice, the immunofluorescent double labelling method was used as described for the wild-type mice given fat-enriched diets. In the APP/PS1 mice, $50 \mu \mathrm{m}$ thick cryosections were fixed with $4 \%$ paraformaldehyde for $1 \mathrm{~h}$ and heat-mediated antigen retrieval was done by incubating the sections in $60^{\circ} \mathrm{C}$ water for $3 \mathrm{~h}$. A mixture of rabbit-derived anti-apo $\mathrm{B}$ and mouse monoclonal anti-A $\beta$ antibodies was applied and incubated for $3 \mathrm{~d}$ at $4{ }^{\circ} \mathrm{C}$. Following washing with PBS, the primary antibodies were detected with anti-rabbit IgG Alexa 488 and anti-mouse IgG1 Alexa 680, respectively. Immunofluorescent 3-D images were captured at $\times 400$ magnification with ApoTome.

\section{Statistical analysis}

There were twelve mice in each dietary group studied. For the immunodetection of $\mathrm{IgG}$, apo B, occludin and vWF, up to
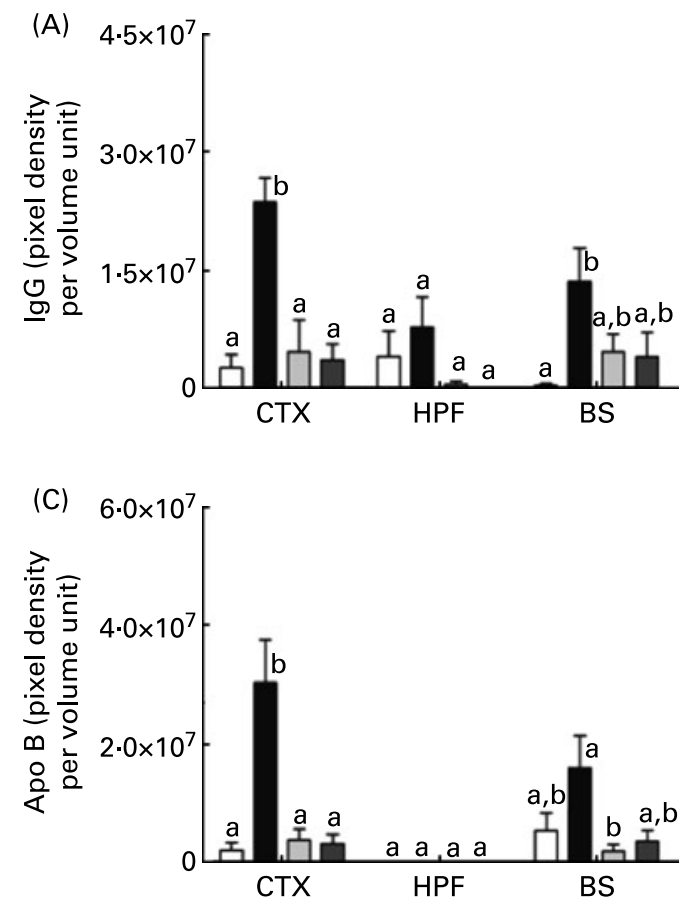

seven 3-D images were obtained for each of the three regions of the brain studied (CTX, HPF and BS). Each 3-D image was generated from a stack of two-dimensional images, consisting of between twenty-two and 181 sequential images. The 3-D stacks represented 4.9-18.5 $\mu \mathrm{m}$ tissue thickness. For co-localisation analysis of apo $B$ with $A \beta$ in SFA-fed mice and in APP/PS1 mice, three to six 3-D images were generated per animal, with ten mice in the SFA group and six mice in the APP/PS1 group. A total of 694 images were analysed in SFA-fed mice and 834 images in transgenic APP/PS1 mice. Data were normally distributed and compared by one-way ANOVA followed by Tukey's post hoc test or Student's $t$ test using SPSS (SPSS, Inc., Chicago, IL, USA). Data were expressed as mean values with their standard errors.

\section{Results}

The fatty acid-supplemented diets given to mice were well tolerated. There was no difference in plasma lipids or body weight following 3 or 6 months of dietary intervention (data not shown).

IgG $(150 \mathrm{kDa})$ immunoreactivity was used as a generic marker of blood-to-brain influx of plasma proteins. In mice fed the SFA diet for 3 months, we identified significant perivascular leakage of $\mathrm{IgG}$ into the CTX, BS and to a lesser extent, within the HPF (Figs. 1 and 2). At 6 months of feeding, IgG leakage was more evident than at 3 months (Figs. 1 and 2). In contrast, in the mice given the low-fat control diet, or either of the unsaturated fatty acid diets, there was no evidence of cerebral IgG immunoreactivity (Fig. 1).
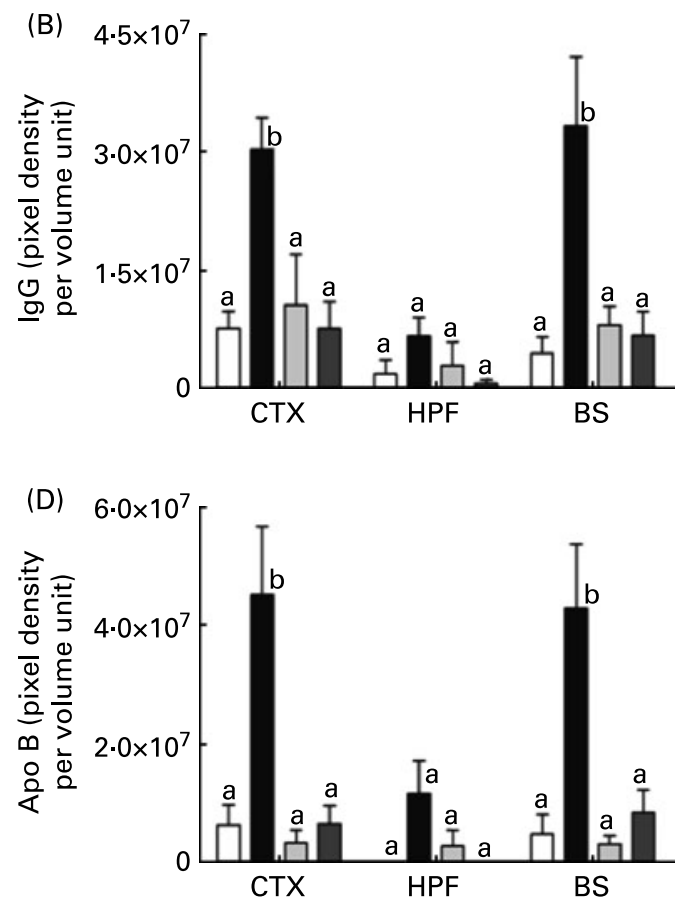

Fig. 2. Three-dimensional (3-D) semi-quantitative analysis of cerebral IgG (A and B) and apo B (C and D) extravasation in mice fed a control diet ( $\square$ ), a SFA-rich diet ( $\square$ ), a MUFA-rich diet ( $\square$ ) or a PUFA-rich diet ( $\square$ ) for 3 months (A and C) or 6 months (B and D). The extent of cerebral IgG and apo B abundance was determined in 3-D based on the optical pixel density. Optical pixel densities were measured in three major brain regions of the cortex (CTX), hippocampal formation (HPF) and brain stem (BS) and expressed as per volume unit. Values are means, with standard errors represented by vertical bars. a,b Mean values, within a region, with unlike letters were significantly different $(P<0.05$; one-way ANOVA). 

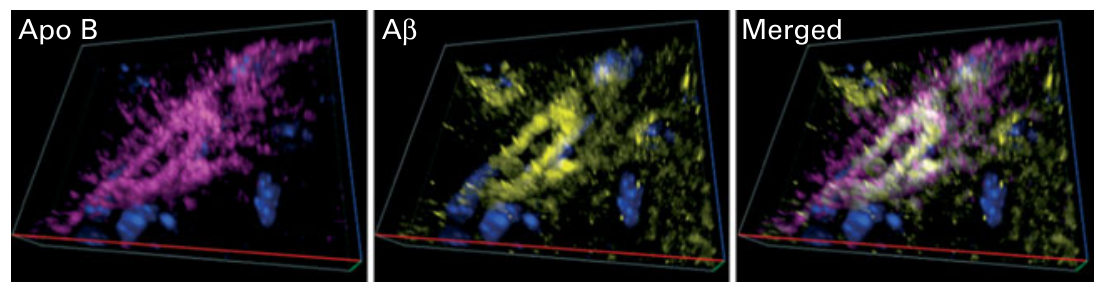

Fig. 3. Co-localisation of amyloid- $\beta(A \beta)$ with perivascualr apo $B$ influx in SFA-fed mice. Significant immunoreactivity of $A \beta$ was detected concomitant with perivascular leakage of apo B lipoproteins in SFA-fed mice, consistent with blood-to-brain delivery of lipoprotein-A $\beta$. The immunofluorescent images were captured in three dimensions $(x, y, z=70 \times 60 \times 11 \mu \mathrm{m})$, and separated single images of apo $B$ (magenta) and $A \beta$ (yellow), and the merged image are shown. The number of co-localising pixels of different fluorescent dyes was measured by AxioVision software ${ }^{\mathrm{TM}}$ (Carl Zeiss, Jena, Germany) utilising Manders' correlation analysis (coefficient $=0.843($ SEM 0.01); $n$ 695).

Apo B was used as a marker of intestinal and hepatically derived lipoprotein influx into the brain. Native apo B lipoproteins are large macromolecules of 3-50 million $\mathrm{kDa}$ molecular weight and a diameter of $>23 \mathrm{~nm}$. In SFA-fed mice, apo B immunoreactivity was visible within the CTX and BS at 3 months following commencement of the diet (Fig. 1). However, ingestion of SFA for 6 months exacerbated apo B extravasation and apo B became more evident within the HPF. Analogous to the findings for IgG, mice maintained on the MUFA-enriched, PUFA-enriched or control diet showed no apo B cerebral immunoreactivity at either 3 or 6 months of feeding (Figs. 1 and 2).

Evidence consistent with the possibility that SFA feeding leads to peripheral delivery to the brain of apo B lipoprotein-associated $A \beta$ is shown in Fig. 3. Perivascular distribution of $A \beta$ is clearly seen coinciding with the distribution of apo $B$ lipoproteins (Manders' correlation coefficient 0.843 (SEM $0.01) ; P<0.0001)$.

To explore if the pattern of cerebral apo $\mathrm{B} / \mathrm{A} \beta$ distribution in SFA mice could be relevant to $\mathrm{AD}$ aetiology, we also investigated $\mathrm{IgG}$ and apo B distribution in 12-month-old APP/PS1 transgenic animals. As found in SFA wild-type mice, the APP/PS1 mice have significant cerebral $\mathrm{IgG}$ and apo B extravasation primarily within the CTX, but with significant amounts also within the HPF (Figs. 4 and 5). In addition, utilising highly sensitive 3-D immunodetection, apo $B$ lipoproteins were clearly visible co-localised with $A \beta$ plaque (Manders' correlation coefficient 0.85 (SEM 0.004); $P<0.0001$; Fig. 6) and plaque abundance positively correlated with apo B immunoreactivity (Pearson's correlation coefficient 0.49 (SEM 0.037)).

BBB integrity was also assessed by determining the abundance of occludin (a tight junction protein) relative to $\mathrm{vWF}$. Both in SFA-fed mice and in APP/PS1 transgenic mice, occludin expression was substantially attenuated compared with controls (Figs. 7 and 8). Further evidence that BBB integrity was compromised was suggested by changes in the plasma concentration of S100B (Fig. 9). In the cerebrospinal fluid, S100B level is orders of magnitude greater than in plasma and therefore serves as a useful surrogate marker of
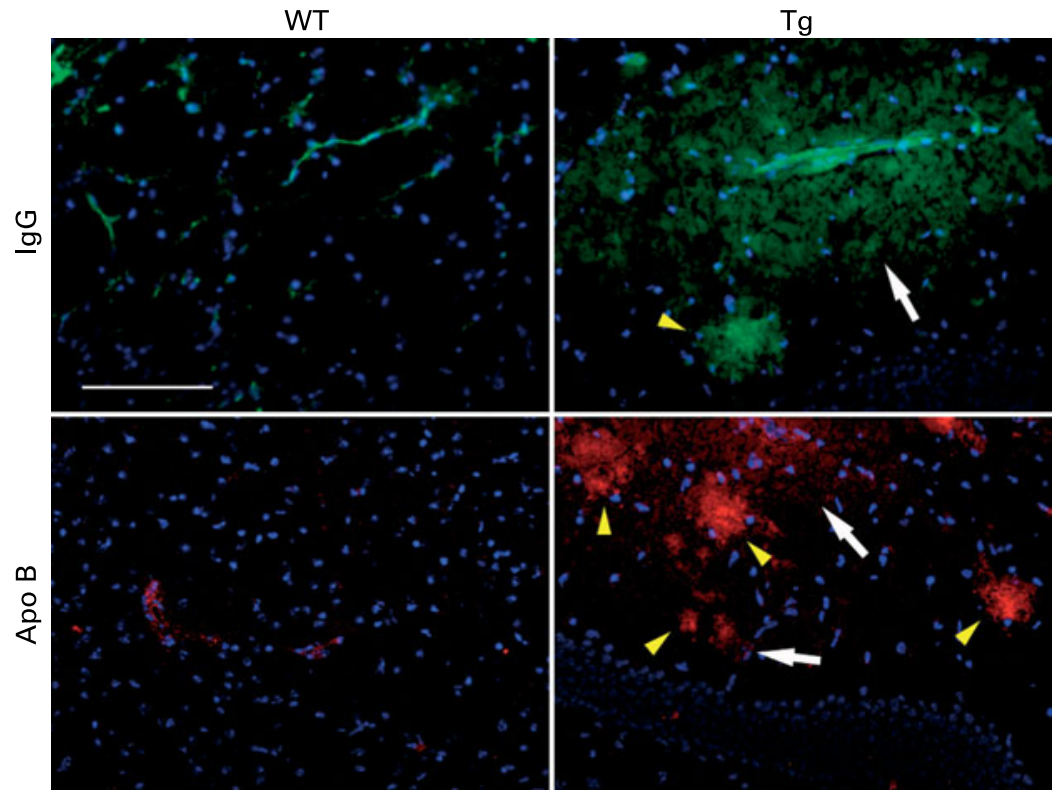

Fig. 4. Three-dimensional (3-D) quantitative immunomicroscopy of cerebral IgG and apo B extravasation in amyloid precursor protein/presenilin-1 (APP/PS1) amyloid transgenic $(\mathrm{Tg})$ mice. The cerebral leakage of plasma IgG and apo B were quantitatively measured by 3-D immunofluorescent detection in the Tg mice. Substantial influx of plasma IgG and apo B into the brain was observed in the Tg mice (white arrows) while no leakages were seen in age-matched wild-type (WT) control mice. Notably, apo B immunoreactivity in the Tg mice strongly co-localised with amyloid plaques (see Fig. 6) while only occasional co-localisation of IgG with plaques was seen (yellow arrow heads). IgG, apo B and nuclei are shown in green, red and blue, respectively. The scale bar indicates $100 \mu \mathrm{m}$. 

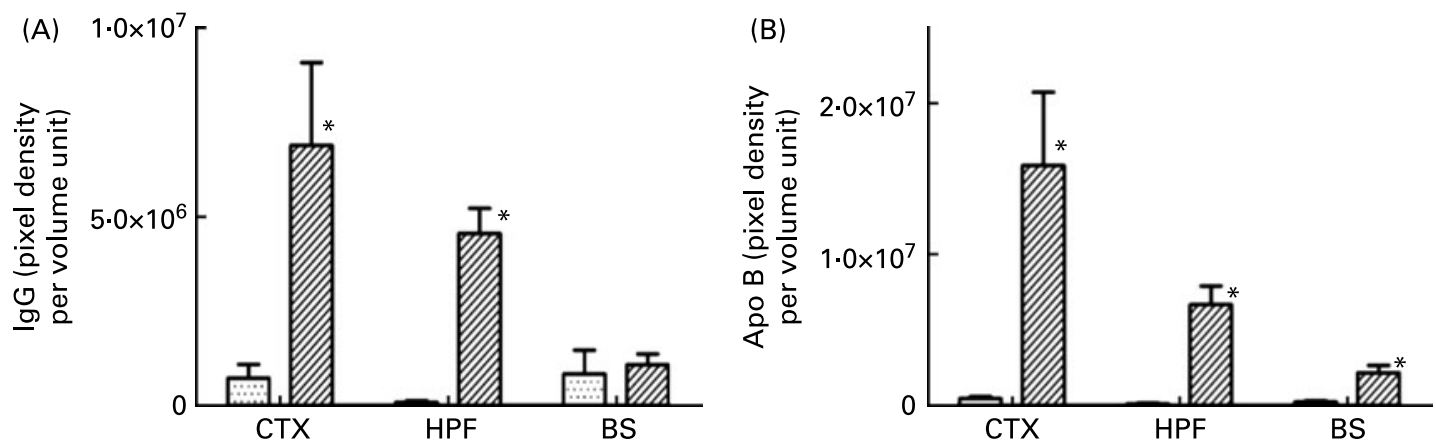

Fig. 5. Three-dimensional semi-quantitative analysis of cerebral $\lg G(A)$ and apo $B(B)$ extravasation in amyloid precursor protein/presenilin-1 (APP/PS1) amyloid transgenic $(\mathrm{Tg} ; \mathrm{s})$ mice. Optical pixel densities were measured in three major brain regions of the cortex (CTX), hippocampal formation (HPF) and brain stem (BS) and expressed as per volume unit. Values are means, with standard errors represented by vertical bars. * Quantitative analysis based on the pixel density suggested significantly increased immunoreactivity of IgG and apo B in the brain of Tg mice compared with wild-type control mice $($ 圆 $)(P<0.05 ; t$ test).

brain-to-blood efflux ${ }^{(32-33)}$. Mice fed SFA had an $80 \%$ increase in plasma $\mathrm{S} 100 \mathrm{~B}$ compared with low fat-fed mice, but there was no difference in mice fed either of the unsaturated fatty acid diets (Fig. 9). Similarly, plasma S100B was more than doubled in APP/PS1 mice.

The breakdown of the BBB and increased influx of TRL$A \beta$ in SFA-fed mice did not appear to be a consequence of exaggerated exposure to circulating $A \beta$, on the basis that the plasma concentration of $A \beta_{1-40}$ and $A \beta_{1-42}$ were similar for all groups of wild-type mice (Fig. 10).

\section{Discussion}

The present study suggests that chronic ingestion of SFA compromises BBB integrity, resulting in blood-to-brain delivery of plasma proteins, including apo B lipoproteins that may be endogenously enriched in $A \beta$. Consistent with the notion of BBB dysfunction in SFA-fed mice, there was evidence of cerebrospinal fluid-to-plasma efflux, with a doubling in the plasma concentration of S100B. The detrimental effect of SFA on BBB function seemed to be specific, as no differences were observed between control animals and mice supplemented with either MUFA or PUFA. The cerebral distribution and co-localisation of $\mathrm{A} \beta$ with apo $\mathrm{B}$ lipoproteins in SFA-fed mice was also found to be remarkably similar to that in APP/PS1 amyloid transgenic mice and in the latter there was a positive association of plasma-derived apo B lipoproteins with cerebral $A \beta$ deposits. The cerebral distribution of apo B and IgG was greater at both 3 and 6 months of
SFA feeding within the CTX than the HPF or BS regions, suggesting a site-specific effect. The observation is consistent with the hypothesis of enhanced blood-to-brain delivery of peripheral lipoprotein-A $\beta$, because the CTX has a more substantial capillary network. Kawai et al. reported that 60-77\% of amyloid plaques were associated with capillaries and relevant to the hypothesis presented in the present study, there was significantly greater vessel density within a $10 \mu \mathrm{m}$ border surrounding plaques compared with unaffected grey matter $^{(34)}$. Collectively, the findings of the present study provide one explanation of how dietary fats may influence $\mathrm{AD}$ risk. Ingestion of SFA could enhance peripheral delivery to the brain of circulating lipoprotein $-\mathrm{A} \beta$ and exacerbate the amyloidogenic cascade.

The fatty acid-enriched diets provided to mice were well tolerated and there were no significant differences in weight gain, plasma cholesterol or plasma TAG between groups. Therefore changes to BBB integrity in SFA-fed mice were not a consequence of dietary induced dyslipidaemia. The diets were physiologically relevant. Palmitic $(16: 0)$ and stearic $(18: 0)$ acid content of the mouse diets of 5.2 and $7.1 \%$ of energy intake, respectively, is comparable with Western patterns of consumption of between 5 and $7 \%$ for each. Total saturates of the mouse chow were also similar to Western dietary patterns (13\% mouse SFA chow $v .14 \%$ in human diets) as well as total digestible energy as lipids (40\% for fatty acid-supplemented chow v. $37 \%$ in Western diets).

We put forward the hypothesis that an SFA-induced elevation in plasma $\mathrm{A} \beta$ might compromise $\mathrm{BBB}$ function on
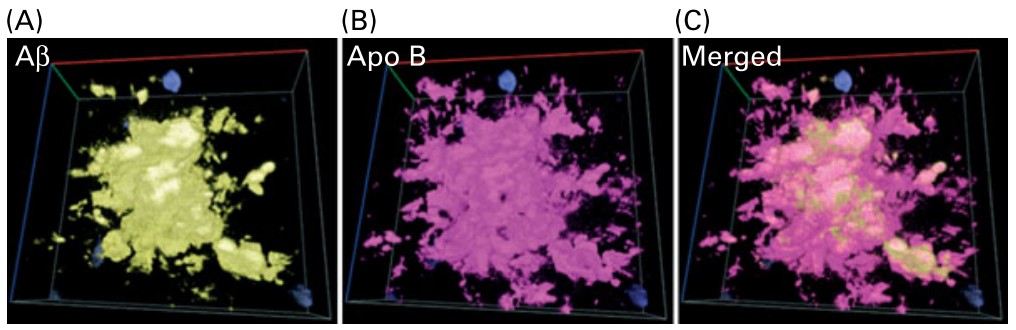

Fig. 6. Co-localisation of apo B with cerebral amyloid plaques. An immunofluorescent double-labelling method was utilised to explore the co-localisation of apo B with amyloid plaques in amyloid precursor protein/presenilin-1 (APP/PS1) transgenic Alzheimer's disease model mice. The distribution of apo B and amyloid- $\beta$ $(A \beta)$ for the same tissue specimen are shown separately ( $A$ and $B)$. The co-location of apo $B$ with $A \beta$ is indicated in the merged image $(C)$. For the latter, $A \beta$ is shown in yellow and apo B is shown in magenta. Scales of $x$ (red), $y$ (blue) and $z$ (green) axes are $70 \times 70 \times 22 \mu \mathrm{m}$. 


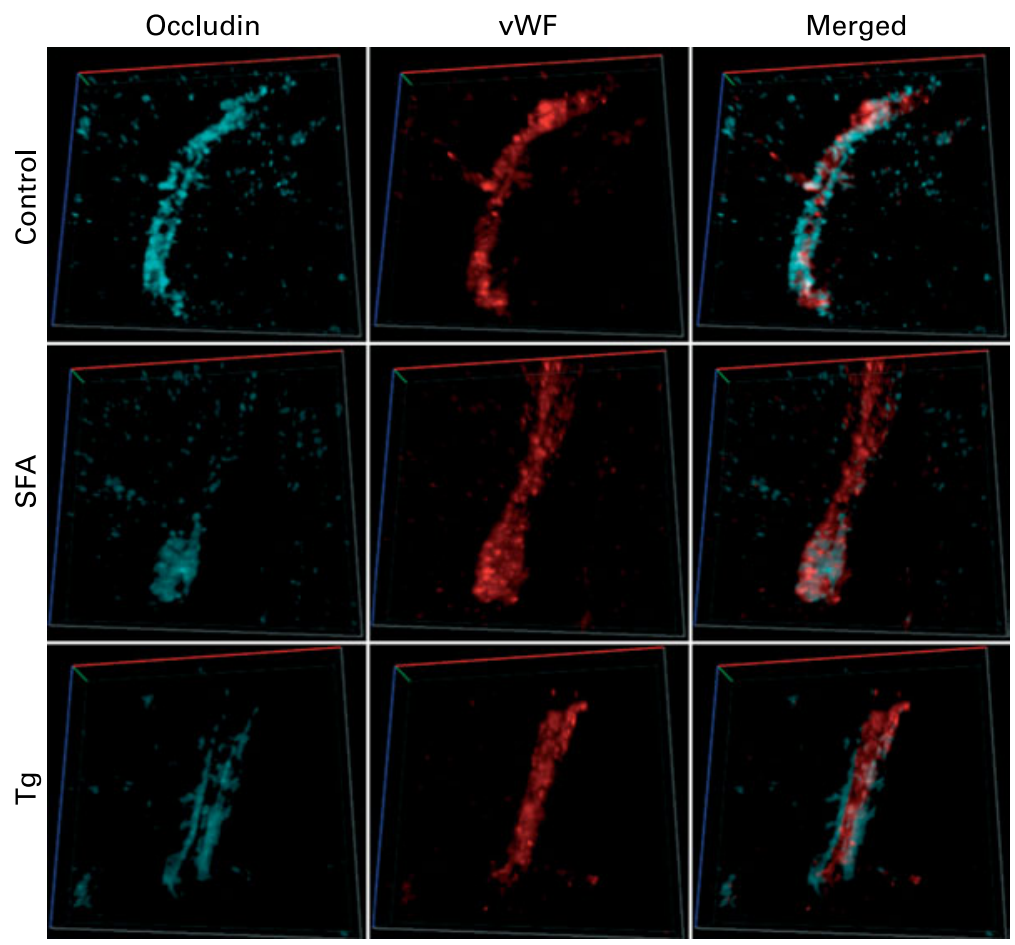

Fig. 7. Blood-brain barrier (BBB) three-dimensional (3-D) detection of the tight junction protein occludin. The expression of occludin-1 relative to epithelial cell abundance (expressed as von-Willebrand factor (VWF)) was quantitatively determined using double-labelling immunofluorescent microscopy. Representative 3-D images of occludin and vWF images are shown $(x, y, z=80 \times 80 \times 7 \mu \mathrm{m})$. Significantly decreased expression of BBB occludin was found in SFA-fed mice compared with control mice, consistent with amyloid precursor protein/presenilin-1 (APP/PS1) amyloid trangenic (Tg) mice.
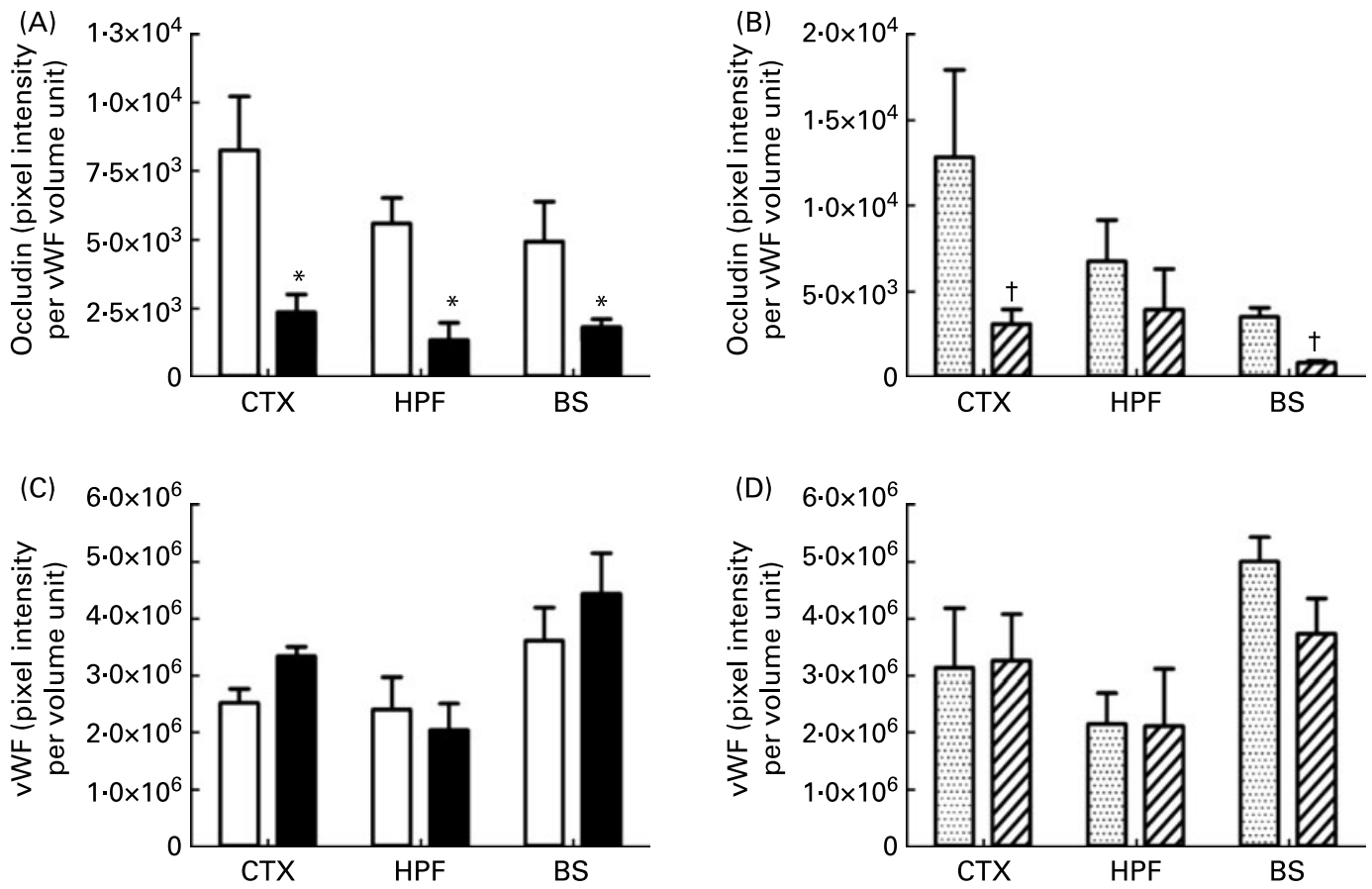

Fig. 8. Three-dimensional semi-quantitative analysis of cerebrovascular occludin (A and B) and von-Willebrand factor (vWF) (C and D) in control ( $\square$ ), SFA-fed

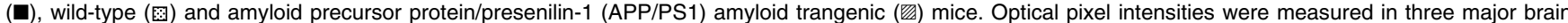
regions of the cortex (CTX), hippocampal formation (HPF) and brain stem (BS). Immunoreactivities of blood-brain barrier occludin-1 are expressed as per vWF volume unit. The net abundance of vWF is indicated per unit tissue. Values are means, with standard errors represented by vertical bars. ${ }^{*}$ Mean value was significantly different from that of the control mice $(P<0.05 ; t$ test). † Mean value was significantly different from that of the wild-type mice $(P<0.05 ; t$ test). 


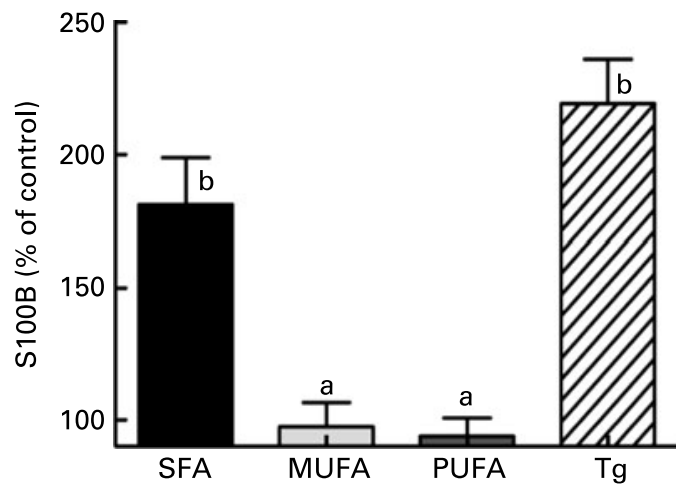

Fig. 9. Plasma level of S100B. Plasma S100B was determined by ELISA as a surrogate marker of brain-to-blood leakage. Mice fed SFA for 3 months had a significantly higher S100B level compared with the control, MUFA- and PUFA-fed mice. Similarly, amyloid precursor protein/presenilin-1 (APP/PS1) amyloid trangenic $(\mathrm{Tg})$ mice had a doubling in plasma $\mathrm{S100B}$ compared with wild-type controls. Values are means, with standard errors represented by vertical bars. ${ }^{a, b}$ Mean values with unlike letters were significantly different $(P<0.01$; one-way ANOVA).

the basis that exogenous administration of this protein showed disturbing vasoreactive properties in vivo. However, in the present study the plasma concentrations of $A \beta_{1-40}$ and $A \beta_{1-42}$ were similar for all groups of wild-type mice. We cannot equivocally rule out an elevation in the lipoprotein pool of $A \beta$ because some studies suggest that lipids block detection of lipoprotein-bound $A \beta^{(35,36)}$.

The SFA diet may have also compromised BBB function mechanisms independent of lipoprotein-A $\beta$ concentration, including enhanced production of reactive oxygen species, increases in intracellular $\mathrm{Ca}$ or activation of endoplasmic reticulum stressors ${ }^{(37-40)}$. Clinical evidence suggests that inflammatory pathways can become activated because of impaired postprandial lipid metabolism ${ }^{(41)}$. Important differences in the cytotoxic effects of fatty acids have been reported, with longer-chain SFA being the most potent and the MUFA and PUFA being cytoprotective ${ }^{(37)}$. Morgan ${ }^{(37)}$ suggests that the underlying toxicity of SFA is a consequence of disturbances in protein processing and endoplasmic reticulum dysfunction, for example, apoptotic induction. Consistent with this hypothesis, Patil et al. reported a palmitic acid-induced regionspecific damage because of a higher fatty acid-metabolising capacity of cortical astroglia ${ }^{(42)}$. Conversely, cell-culture

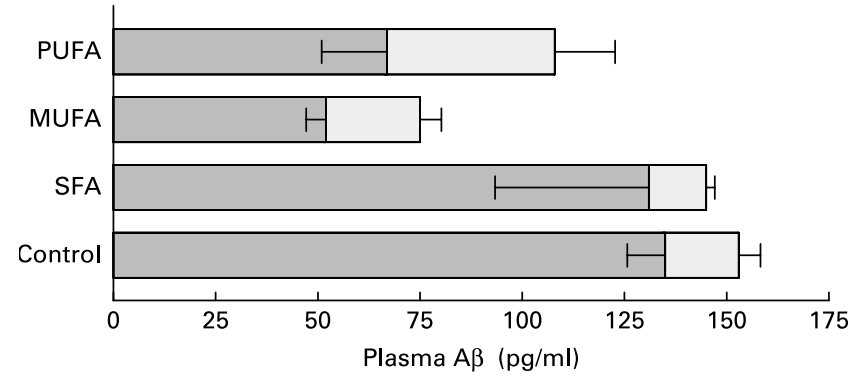

Fig. 10. Plasma amyloid- $\beta(A \beta)$ concentration in control and high fatty acidfed mice. Plasma levels of $A \beta_{1-40}(\square)$ and $A \beta_{1-42}(\square)$ were measured with ELISA. Values are means, with standard errors represented by horizontal bars. There was no significant difference between the control group and any of the high-fat treatment groups. studies suggest that incubation, particularly with longerchain unsaturates, has an antagonistic effect on endoplasmic reticulum-centred stress pathways ${ }^{(43)}$.

Dietary 'lipotoxicity' refers to the processes leading to endorgan damage and/or dysfunction following excess exposure to fatty acids and was first coined in the context of fat-induced insulin resistance ${ }^{(44)}$. Since then, however, the process has also been implicated in endothelial dysfunction and atherosclerosis, heart failure, kidney failure, steatohepatitis and liver failure, autoimmune inflammatory disorders, susceptibility to infections, cancer and ageing. The BBB disturbances identified in the present study may reflect a broader dietary toxic phenomenon.

SFA may also have compromised BBB function by secondary pathways other than elevations in plasma $A \beta$, or as a consequence of interactive effects with genes involved in $\mathrm{A} \beta$ metabolism and $\mathrm{BBB}$ function. For example, Deane et al. showed that apoE isoforms differentially regulate $A \beta$ clearance from the brain by routing free $A \beta$ through alternate receptors at the BBB. Apo E4-facilitated efflux was slower than apo E3- or apo E2-mediated clearance ${ }^{(45,46)}$. The effect of SFA on apo $\mathrm{E}$ isoforms was not explored in the present study.

Apo B immunoreactivity in senile plaque of subjects with $\mathrm{AD}$ was reported some years ago ${ }^{(47)}$ but there was no evidence that this association was causal. However, several lines of study are consistent with the concept that peripheral delivery of lipoprotein-A $\beta$ may contribute to $\mathrm{AD} \operatorname{risk}^{(5,18,48-50)}$. Firstly, $A \beta$ is tightly bound to TRL, the secretion of which is positively associated with the onset and progression of cerebrovascular and parenchymal amyloidosis ${ }^{(20-21)}$. Indirect evidence for the possibility of enhanced lipoprotein-mediated blood-to-brain delivery of $A \beta$ is suggested by the study of Kreuter et al. who demonstrated enhanced drug transport into the brain when nanoparticles were covalently attached to apolipoproteins (including apo B) ${ }^{(51)}$. In clinical studies significantly greater levels of apo B are found in AD patients ${ }^{(52)}$ and indirect evidence also comes from studies investigating the pro-atherogenic properties of apo B lipoproteins, a disease that shares some pathological similarities to $\mathrm{AD}$. In arterial tissue, apo B lipoproteins and particularly the post-hydrolysed remnants of apo B lipoproteins have significant affinity for extracellular matrices and, if trapped, induce an inflammatory response $^{(53)}$. The uptake by resident macrophages of apo B lipoproteins triggers a respiratory burst compromising cell viability leading to atherosclerotic plaque instability ${ }^{(54)}$. Obesity and diabetes also significantly increase risk for $\mathrm{AD}^{(55)}$. Profenno et al. ${ }^{(55)}$ suggested that physiological changes common to obesity and diabetes plausibly promote AD. Resistance to the action of insulin in obese/diabetic individuals results in hepatic and intestinal apo B lipoprotein overproduction, diminished clearance of apo B lipoproteins from blood and postprandial dyslipidaemia ${ }^{(56)}$. It is possible that the cerebral parenchymal entrapment of lipoprotein-A $\beta$ and formation of fibrillar deposits share pathways in common with the initiation of progression of atherosclerosis.

Nelson \& Alkon ${ }^{(57)}$ suggested that fibrillar formation of $A \beta$ is prevented by proteins such as apo B that have affinity for the $A \beta$ hydrophobic domain. Using a phage display system to explore protein-protein interaction, they found that $A \beta$ binds to proteins primarily involved in LDL and cholesterol 
transport. However, given that apo B is a protein not normally found in cerebrospinal fluid it is unlikely to serve as a suppressor of amyloidosis. Rather, cerebrovascular remodelling of apo $B$ lipoprotein $-\mathrm{A} \beta$ delivered to the brain could exacerbate amyloidogenesis as a result of $A \beta$ release, or enhanced epitope exposure ${ }^{(30)}$

There is an accumulating body of literature consistent with the concept that the onset and progression of $\mathrm{AD}$ is influenced by lifestyle factors including nutrition. Population studies support a role of dietary fats in AD. Laitinen et al. reported that intake of unsaturated fats is protective, whereas intake of saturates increases risk of $\mathrm{AD}^{(58)}$. In the Framingham study, the top quartile of plasma DHA was associated with a $47 \%$ reduction in risk of all-cause dementia ${ }^{(59)}$. Furthermore, evidence continues to come from animal studies including by Oksman et al. who confirmed that saturates increase, while DHA decreases, cerebral A $\beta$ levels compared with a soya oil diet ${ }^{(60)}$.

The present study provides novel insight into how dietary fats might influence $\mathrm{AD}$ risk and reports for the first time differential effects of dietary fatty acids on BBB integrity. Mice chronically fed SFA show significant blood-to-brain delivery, retention and accumulation of apo B lipoproteins, primarily within the CTX of SFA-fed mice, observations consistent with the distribution of apo $\mathrm{B}$ in amyloid in brain specimens from subjects with $\mathrm{AD}$. In the present study, chronic ingestion of SFA in wild-type mice also replicated the pattern of $\mathrm{BBB}$ dysfunction and of TRL-A $\beta$ distribution observed in an established model of AD (APP/ PS1 transgenics) maintained on normal chow. How dietary behaviour influences $\mathrm{BBB}$ function and the propensity for amyloidosis may prove helpful in the context of $\mathrm{AD}$ prevention.

\section{Acknowledgements}

The present study was financially supported by the National Health and Medical Research Council of Australia, and the Australian Technology Network Centre for Metabolic Fitness.

R. T. conducted the experimental procedures and prepared the manuscript. S. G. contributed to the animal care and experimental data collection. M. M. S. P.-G. contributed to experimental data collection. C. L. W. contributed to animal sample preparation. R. D. J. contributed to the development of methods. S. S. D. contributed to the experimental design and statistical assessment. J. C. L. M. contributed to the project concept, research funding, experimental design, data collection and writing of the manuscript.

The authors declare no conflicts of interest.

\section{References}

1. Pasinetti GM \& Eberstein JA (2008) Metabolic syndrome and the role of dietary lifestyles in Alzheimer's disease. J Neurochem 106, 1503-1514.

2. Kalmijn S (2000) Fatty acid intake and the risk of dementia and cognitive decline: a review of clinical and epidemiological studies. J Nutr Health Aging 4, 202-207.

3. Petot GJ \& Friedland RP (2004) Lipids, diet and Alzheimer's disease: an extended summary. J Neurol Sci 226, 31-33.
4. Sparks DL, Scheff SW, Hunsaker JC III, et al. (1994) Induction of Alzheimer-like $\beta$-amyloid immunoreactivity in the brains of rabbits with dietary cholesterol. Exp Neurol 126, 88-94.

5. Refolo LM, Malester B, LaFrancois J, et al. (2000) Hypercholesterolemia accelerates the Alzheimer's amyloid pathology in a transgenic mouse model. Neurobiol Dis 7, 321-331.

6. Ellis RJ, Olichney JM, Thal LJ, et al. (1996) Cerebral amyloid angiopathy in the brains of patients with Alzheimer's disease: the CERAD experience, Part XV. Neurology 46, 1592-1596.

7. Kalaria RN (1992) The blood-brain barrier and cerebral microcirculation in Alzheimer disease. Cerebrovasc Brain Metab Rev 4, 226-260.

8. Wisniewski HM, Vorbrodt AW \& Wegiel J (1997) Amyloid angiopathy and blood-brain barrier changes in Alzheimer's disease. Ann NY Acad Sci 826, 161-172.

9. Cullern KM (1997) Perivascular astrocytes within Alzheimer's disease plaques. Neuroreport 8, 1961-1966.

10. Itagaki S, McGeer PL, Akiyama H, et al. (1989) Relationship of microglia and astrocytes to amyloid deposits of Alzheimer disease. J Neuroimmunol 24, 173-182.

11. Hachinski V \& Munoz DG (1997) Cerebrovascular pathology in Alzheimer's disease: cause, effect or epiphenomenon? Ann NY Acad Sci 826, 1-6.

12. Joachim CL, Duffy LK, Morris JH, et al. (1988) Protein chemical and immunocytochemical studies of meningovascular $\beta$-amyloid protein in Alzheimer's disease and normal aging. Brain Res 474, 100-111.

13. Deane R, Sagare A, Hamm K, et al. (2005) IgG-assisted age-dependent clearance of Alzheimer's amyloid $\beta$ peptide by the blood-brain barrier neonatal Fc receptor. J Neurosci $\mathbf{2 5}$, $11495-11503$.

14. Mackic JB, Bading J, Ghiso J, et al. (2002) Circulating amyloid- $\beta$ peptide crosses the blood-brain barrier in aged monkeys and contributes to Alzheimer's disease lesions. Vascul Pharmacol 38, 303-313.

15. Crossgrove JS, Li GJ \& Zheng W (2005) The choroid plexus removes $\beta$-amyloid from brain cerebrospinal fluid. Exp Biol Med 230, 771-776.

16. Donahue JE, Flaherty SL, Johanson CE, et al. (2006) RAGE, LRP-1, and amyloid- $\beta$ protein in Alzheimer's disease. Acta Neuropathol 112, 405-415.

17. Galloway S, Jian L, Johnsen R, et al. (2007) $\beta$-Amyloid or its precursor protein is found in epithelial cells of the small intestine and is stimulated by high-fat feeding. J Nutr Biochem 18, 279-284.

18. Takechi R, Galloway S, Pallebage-Gamarallage MMS, et al. (2008) Chylomicron amyloid- $\beta$ in the aetiology of Alzheimer's disease. Atheroscler Supp 9, 19-25.

19. Koudinov AR \& Koudinova NV (1997) Alzheimer's soluble amyloid $\beta$ protein is secreted by HepG2 cells as an apolipoprotein. Cell Biol Int 21, 265-271.

20. James AP, Pal S, Gennat HC, et al. (2003) The incorporation and metabolism of amyloid- $\beta$ into chylomicron-like lipid emulsions. J Alzeimers Dis 5, 179-188.

21. Mamo JC, Jian L, James AP, et al. (2008) Plasma lipoprotein $\beta$-amyloid in subjects with Alzheimer's disease or mild cognitive impairment. Ann Clin Biochem 45, 395-403.

22. Smith D, Watts GF, Dane-Stewart C, et al. (1999) Post-prandial chylomicron response can be predicted by a single measurement of plasma apolipoprotein B48 in the fasting state. Eur J Clin Invest 29, 204-209.

23. Boyt AA, Taddei TK, Hallmayer J, et al. (2000) The effect of insulin and glucose on the plasma concentration of Alzheimer's amyloid precursor protein. Neuroscience 95, 727-734.

24. LaRue B, Hogg E, Sagare A, et al. (2004) Method for measurement of the blood-brain barrier permeability in the perfused mouse brain: application to amyloid- $\beta$ peptide in wild type 
and Alzheimer's Tg2576 mice. J Neurosci Methods 138, 233-242.

25. Burgess BL, McIsaac SA, Naus KE, et al. (2006) Elevated plasma triglyceride levels precede amyloid deposition in Alzheimer's disease mouse models with abundant A $\beta$ in plasma. Neurobiol Dis 24, 114-127.

26. Arendash GW, Su GC, Crawford FC, et al. (1999) Intravascular $\beta$-amyloid infusion increases blood pressure: implications for a vasoactive role of $\beta$-amyloid in the pathogenesis of Alzheimer's disease. Neurosci Lett 268, 17-20.

27. Maness LM, Banks WA, Podlisny MB, et al. (1994) Passage of human amyloid $\beta$-protein ${ }_{1-40}$ across the murine blood-brain barrier. Life Sci 55, 1643-1650.

28. Thomas T, McLendon C, Sutton ET, et al. (1997) Cerebrovascualr endothelial dysfunction mediated by $\beta$-amyloid. Neuroreport 8, 1387-1391.

29. Natah SS, Mouihate A, Pittman QJ, et al. (2005) Disruption of the blood-brain barrier during TNBS colitis. Neurogastroenterol Motil 17, 433-446.

30. Kay AD, Day SP, Nicoll JA, et al. (2003) Remodelling of cerebrospinal fluid lipoproteins after subarachnoid hemorrhage. Atherosclerosis 170, 141-146.

31. Takechi R, Galloway S, Pallebage-Gamarallage MM, et al. (2008) Three-dimensional immunofluorescent double labelling using polyclonal antibodies derived from the same species: enterocytic colocalization of chylomicrons with Golgi apparatus. Histochem Cell Biol 129, 779-784.

32. Kleindienst A, Hesse F, Bullock MR, et al. (2007) The neurotrophic protein S100B: value as a marker of brain damage and possible therapeutic implications. Prog Brain Res 161, 317-325.

33. Yang Q, Hou X, Hamberger A, et al. (1995) S-100 $\beta$ immunoreactivity in neurons of the rat peripheral sensory ganglia. Neuroreport 6, 2005-2009.

34. Kawai M, Kalaria RN, Harik SI, et al. (1990) The relationship of amyloid plaques to cerebral capillaries in Alzheimer's disease. Am J Pathol 137, 1435-1446.

35. Yanagisawa K, McLaurin J, Michikawa M, et al. (1997) Amyloid $\beta$-protein (A $\beta$ ) associated with lipid molecules: immunoreactivity distinct from that of soluble A $\beta$. FEBS Lett 420, 43-46.

36. James AP \& Mamo JC (2005) The immunodetection of lipoprotein-bound amyloid- $\beta$ is attenuated because of the presence of lipids. Ann Clin Biochem 42, 70-72.

37. Morgan NG (2009) Fatty acids and $\beta$-cell toxicity. Curr Opin Clin Nutr Metab Care 12, 117-122.

38. Carpentier AC (2008) Postprandial fatty acid metabolism in the development of lipotoxicity and type 2 diabetes. Diabetes Metab 34, 97-107.

39. Cnop M, Igoillo-Esteve M, Chunha DA, et al. (2008) An update on lipotoxic endoplasmic reticulum stress in pancreatic $\beta$-cells. Biochem Soc Trans 36, 909-915.

40. Solfrizzi V, Frisardi V, Capurso C, et al. (2009) Dietary fatty acids in dementia and predementia syndromes: epidemiological evidence and possible underlying mechanisms. Ageing Res Rev (epublication ahead of print version 28 July 2009).

41. Van oostrom AJ, Alipour A, Plokker TW, et al. (2007) The metabolic syndrome in relation to complement component 3 and postprandial lipemia in patients from an outpatient lipid clinic and healthy volunteers. Atherosclerosis 190, 167-173.

42. Patil S, Balu D, Melrose J, et al. (2008) Brain region-specificity of palmitic acid-induced abnormalities associated with Alzheimer's disease. BMC Res Notes 1, 20.
43. Diakogiannaki E \& Morgan NG (2008) Differential regulation of the ER stress response by long-chain fatty acids in the pancreatic $\beta$-cell. Biochem Soc Trans 36, 959-962.

44. Unger RH (1995) Lipotoxicity in the pathogenesis of obesitydependent NIDDM. Genetic and clinical implications. Diabetes 44, 863-870.

45. Deane R, Sagare A, Hamm K, et al. (2008) ApoE isoformspecific disruption of amyloid $\beta$ peptide clearance from mouse brain. J Clin Invest 118, 4002-4013.

46. Deane R, Bell RD, Sagare A, et al. (2009) Clearance of amyloid- $\beta$ peptide across the blood-brain barrier: implication for therapies in Alzheimer's disease. CNS Neurol Disord Drug Targets $\mathbf{8}, 16-30$.

47. Namba Y, Tsuchiya H \& Ikeda K (1992) Apolipoprotein B immunoreactivity in senile plaque and vascular amyloids and neurofibrillary tangles in the brains of patients with Alzheimer's disease. Neurosci Lett 134, 264-266.

48. Cole GM \& Ard MD (2000) Influence of lipoproteins on microglial degradation of Alzheimer's amyloid $\beta$-protein. Microsc Res Tech 50, 316-324.

49. Clifford PM, Zarrabi S, Siu G, et al. (2007) A $\beta$ peptides can enter the brain through a defective blood-brain barrier and bind selectively to neurons. Brain Res 1142, 223-236.

50. Takechi R, Galloway S, Pallebage-Gamarallage M, et al. (2009) Three-dimensional colocalization analysis of plasma-derived apolipoprotein B with amyloid plaques in APP/PS1 transgenic mice. Histochem Cell Biol 131, 661-666.

51. Kreuter J, Hekmatara T, Dreis S, et al. (2007) Covalent attachment of apolipoprotein A-I and apolipoprotein B-100 to albumin nanoparticles enables drug transport into the brain. J Control Release 118, 54-58.

52. Caramelli P, Nitrini R, Maranhao R, et al. (1999) Increased apolipoprotein B serum concentration in Alzheimer's disease. Acta Neurol Scand 100, 61-63.

53. Mamo JC, Proctor SD \& Smith D (1998) Retention of chylomicron remnants by arterial tissue; importance of an efficient clearance mechanism from plasma. Atherosclerosis 141, S63-S69.

54. Elsegood CL, Pal S, Roach PD, et al. (2001) Binding and uptake of chylomicron remnants by primary and THP-1 human monocyte-derived macrophages: determination of binding proteins. Clin Sci 101, 111-119.

55. Profenno LA, Porsteinsson AP \& Faraone SV (2009) Metaanalysis of Alzheimer's disease risk with obesity, diabetes and related disorders. Biol Psychiatry (epublication ahead of print version 7 April 2009).

56. Mamo JC, Watts GF, Barrett PH, et al. (2001) Postprandial dyslipidemia in men with visceral obesity: an effect of reduced LDL receptor expression? Am J Physiol Endocrinol Metab 281, E626-E632.

57. Nelson TJ \& Alkon DL (2007) Protection against $\beta$-amyloidinduced apoptosis by peptides interacting with $\beta$-amyloid. J Biol Chem 282, 31238-31249.

58. Laitinen MH, Ngandu T, Rovio S, et al. (2006) Fat intake at midlife and risk of dementia and Alzheimer's disease: a population based study. Dement Geriatr Cogn Disord 22, 99-107.

59. Schaefer EJ, Bongard V, Beiser AS, et al. (2006) Plasma phosphatidylcholine docosahexaenoic acid content and risk of dementia and Alzheimer disease: the Framingham Heart Study. Arch Neurol 63, 1545-1550.

60. Oksman M, Iivonen H, Hogyes E, et al. (2006) Impact of different saturated fatty acid, polyunsaturated fatty acid and cholesterol containing diets on $\beta$-amyloid accumulation in APP/PS1 trangenic mice. Neurobiol Dis 23, 563-572. 